\title{
ALTURA E DIÂMETRO DE MUDAS DE Euterpe edulis Martius SUBMETIDAS A DIFERENTES NÍVEIS DE SOMBREAMENTOS E MANEJO HÍDRICO
}

\author{
Guilherme Bravim Canal' \\ Jonas Souza Vinco² \\ Karen Andreon Viçosi ${ }^{3}$ \\ José Eduardo Macedo Pezzopane ${ }^{4}$ \\ Rodrigo Alexandre Sobreira ${ }^{5}$
}

\begin{abstract}
Resumo: O palmiteiro juçara (Euterpe edulis Mart.) é uma espécie ameaçada de extinção devido a exploração predatória de palmito. A propagação desta espécie é um entrave, visto que suas sementes têm germinação lenta e alta taxa de mortalidade, sendo que a qualidade das mudas é essencial para o sucesso da perpetuação da espécie em florestas plantadas. O experimento foi realizado com objetivo de avaliar o crescimento inicial de mudas de palmito juçara sob as condições de disponibilidade de luz (0\%, 30\%, 50\% e $80 \%$ de sombreamento) e sobre manejos hídricos (100\% e 50\% da capacidade de campo). Para avaliação da qualidade das mudas, foram avaliadas a altura e diâmetro do coleto por serem expressivos estimadores morfológicos. A altura e diâmetro das mudas mantidas em capacidade de campo foram maiores até $40 \%$ de sombreamento, enquanto as mudas submetidas ao déficit hídrico obtiveram maior altura em maiores níveis de sombreamento e diâmetro maior até $50 \%$ de sombreamento.
\end{abstract}

Palavras-chave: Palmito Juçara; Déficit hídrico; Espécie nativa.

\footnotetext{
${ }^{1}$ Engenharia Florestal/Universidade Federal do Espírito Santo, Brasil. E-mail: guilhermebravim@hotmail.com

${ }^{2}$ Engenharia Florestal/Universidade Federal do Espírito Santo, Brasil. E-mail: jonasvinco@gmail.com

${ }^{3}$ Agronomia/Universidade Federal do Espírito Santo, Brasil. E-mail: guilhermebravim@hotmail.com

${ }^{4}$ Professor ajunto/Departamento de Ciências Florestais e da Madeira//Universidade Federal do Espírito Santo, Brasil. E-mail: pezzopane2007@yahoo.com.br

${ }_{5}^{5}$ Professor ajunto/Departamento de Ciências Florestais e da Madeira//Universidade Federal do Espírito Santo, Brasil. E-mail: rodrigosobreiraalexandre@gmail.com
} 